\title{
Femoral Offset and its Relationship to Femoral Neck-shaft Angle and Torsion Angle
}

\author{
Desplazamiento Femoral y su Relación con el Ángulo \\ Cuello-Diáfisis Femoral y el Ángulo de Torsión
}

\author{
Ming Han*; Yongkui Zhang* \& Tao Shan**
}

HAN, M.; ZHANG, Y. \& SHAN, T. Femoral offset and its relationship to femoral neck-shaft angle and torsion angle. Int. J. Morphol., 32(4):1194-1198, 2014.

SUMMARY: The aims to study the femoral offset and its relationship to femoral neck-shaft angle and torsion angle. One hundred paired (50 males and 50 females) Chinese femurs were used to measure the femoral offset, femoral neck-shaft angle and torsion angle. The data were analyzed by SPSS software. Femoral offsets were male right $44.40 \pm 4.56 \mathrm{~mm}$, left $42.70 \pm 4.95 \mathrm{~mm}$; female right $39.90 \pm 6.00 \mathrm{~mm}$, left $38.90 \pm 6.18 \mathrm{~mm}$. Femoral torsion angles were male right $6.02 \pm 10.85^{\circ}$, left $7.08 \pm 9.30^{\circ}$; female right $10.02 \pm 11.69{ }^{\circ}$ left $6.02 \pm 10.85^{\circ}$. Neck-shaft angles were male right $131.80 \pm 4.36^{\circ}$, left $134.00 \pm 4.78^{\circ}$; female right $132.10 \pm 5.94^{\circ}$, left $_{132.80 \pm 4.93^{\circ}}$. There were no sexual differences in the two femoral angles $(\mathrm{P}>0.05)$ while there was a significant sexual difference in the femoral offset $(\mathrm{P}<0.01)$. The differences between left and right femoral offset and neck-shaft angle were significant $(\mathrm{P}<0.01)$. Clinically, our results indicate that FO could be obtained using the regression equation when the torsion angle and/or neck-shaft angle is measured.

KEY WORDS: Femoral offset; Femoral neck-shaft angle; Femoral torsion angle; Design of prosthesis.

\section{INTRODUCTION}

Femoral offset (FO), defined as the perpendicular distance from the center of rotation (COR) of the femoral head to the long axis of the femur, is an important reflection of the displacement of the femur from the pelvis. It determines the variation in stress of proximal femur, and also has an important influence on the mode and range of motion (ROM) of the lower limb.

The goal of total hip arthroplasty (THA) is to reconstruct the biomechanics of the hip that has been destroyed by arthritis or fracture. The arthritic hip has lost cartilage, which causes the femoral head to slide and migrate away from the normal hip COR (Dastane et al., 2011), and changes the FO. Therefore, one of the main challenges of THA is to provide optimal FO. It has been reported that failure to reproduce FO in THA will result in limp, fatigue, impingement, and dislocation (Barrack, 1998). It also might lead to increase joint reaction forces and polyethylene (PE) wear (Devane \& Horne, 1999). Little et al. (2009) suggested that linear and volumetric wear of ultrahigh-molecular weight PE would increase by $33 \%$ and $32 \%$, respectively, if FO could not be restored to within $5 \mathrm{~mm}$ of normal native hip. Another study indicates that a difference in the FO postoperatively is often the result of a larger neck-shaft angle of the prosthesis than the patient's own anatomy (McGrory et al., 1995). Consequently, selection of a suitable prosthesis that will provide optimal FO, is an important factor affecting the outcome of THA. Therefore, obtaining accurate data of FO to guide the design of prosthesis and THA has become the object of the present research. In present studies, the measurement methods of FO had been mentioned, for instance, X-ray (Merle et al., 2013), CT-scan (Pasquier et al., 2010), Quantitative computed tomography (QCT) (Ramamurthi et al., 2012), imageless navigation system (Renkawitz et al., 2009). However, the FO data obtained from these methods mostly depended on imaging technique, and $\mathrm{FO}$ was frequently underestimated or overestimated. To our knowledge, there are no data regarding FO in femur specimen and even Chinese specimen.

In this study, we measured the FO in Chinese femur specimen, and analyzed the relationship of FO to femoral neck-shaft angle and torsion angle. We make attempt to obtain more accurate data of FO in this study, and to find the

\footnotetext{
* Department of Orthopedics, Affiliated Hospital of Shandong University of Traditional Chinese Medicine, Shandong Province, China.

** Medical College, Qingdao University, Shandong Province, China.
} 
regression equation between $\mathrm{FO}$, femoral neck-shaft angle and torsion angle, which could provide a more simple method to obtain FO and could effectively guide the design of prosthesis and THA to Chinese.

\section{MATERIAL AND METHOD}

Specimens. We obtained 100 pairs of intact femur specimens provided by the Medical College of Qingdao University (Qingdao, China). The specimens were specially engaged in research study, and 50 pairs of male femur specimens and 50 pairs of female femur specimens were included. Mean the male donors' age was 58.3 years (range, 44-77 years). And mean the female donor's age was 59.7 years (range, 47-79 years). There was no significant difference on age between the female and male donors $(\mathrm{P}>0.05)$. This study was conducted in accordance with the declaration of Helsinki. This study was conducted with approval from the Ethics Committee of Qingdao University.

Measurements. In the diameter line of a plastic transparent trigonal angulometer (Deli Stationery, Ningbo, China), millimeter scale was marked. In the median line of a Plexiglas (Deli Stationery, Ningbo, China) $40 \mathrm{~cm}$ in length, $1 \mathrm{~cm}$ in width, and $0.5 \mathrm{~cm}$ in depth, a straight slot was carved using a bush-hook and filled with black pigment. Two holes were made through the center of the angulometer and the distal end of the Plexiglas strip, respectively. Then, the angulometer and the Plexiglass strip were linked to be a gauge with a mandrin. The femur was placed on a horizontal glass plate, and the axis of femur neck and shaft of femur, and the center of femur head were marked.

Torsion angle. The straight edge of the angulometer was laid flat on the glass plate, and the guard line of the Plexiglas strip was parallel to the axis of the femoral neck. The torsion angle was obtained in the gauge (Fig. 1).

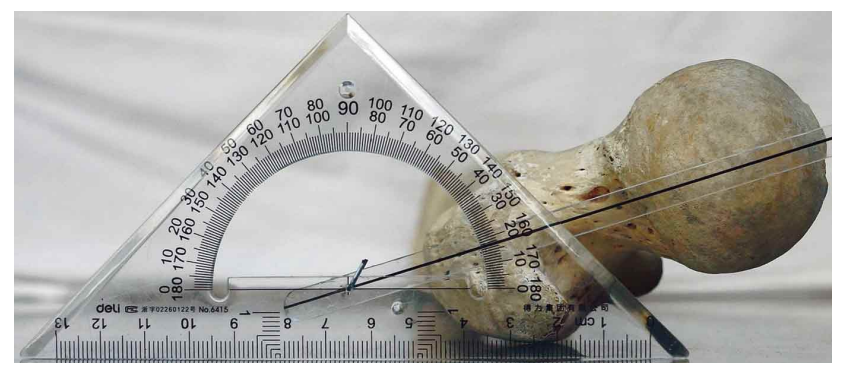

Fig. 1. Measuring femoral torsion angle.

Neck-shaft angle. The plane of the angulometer was parallel to the plane of the glass plate, and the angulometer was abutted the femur. Simultaneously, the guard line of the Plexiglass strip and the diameter line of the angulometer were respectively parallel to the axis of the shaft and femoral neck. The neck-shaft angle was obtained in the gauge (Fig. 2).

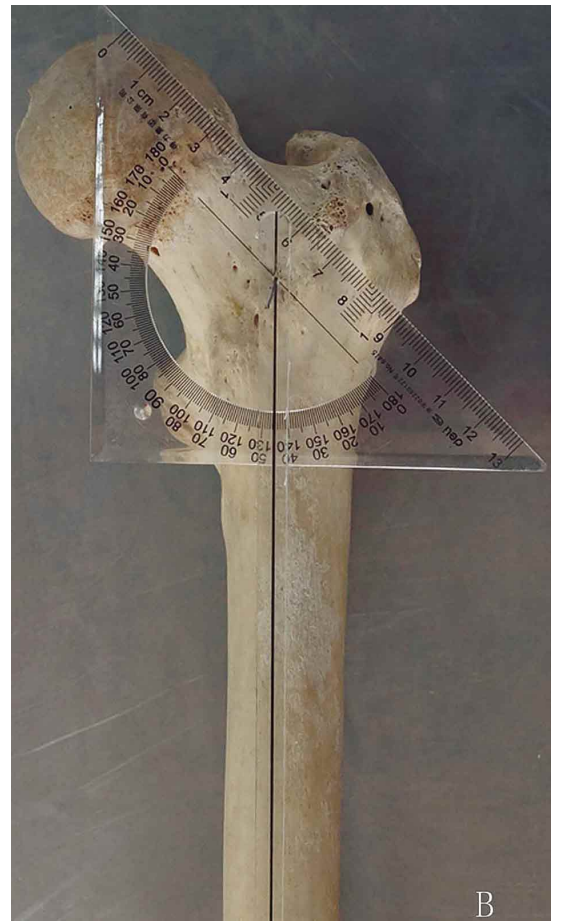

Fig. 2. Measuring femoral neck-shaft angle.

Femoral offset (FO). The plane of the angulometer was parallel to the plane of the glass plate, and the angulometer abutted to the femur. The guard line of the Plexiglass strip was parallel to the axis of the femoral shaft, and was fixed with the angulometer at a $90^{\circ}$ angle. The perpendicular distance from the center of the femoral head to the axis of the femur, namely the femoral offset (FO), was displayed at the graduation line of the angulometer (Fig. 3). If the distance exceeded the graduation line of the angulometer, FO was measured with an electronic vernier caliper.

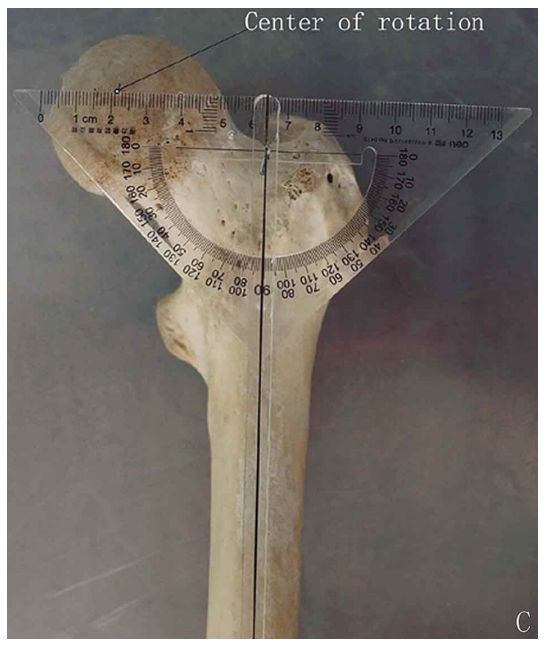

Fig. 3. Measuring femoral offset. 
Statistical analysis. Statistical analyses were performed using SPSS software 16.0 (SPSS Inc, Chicago, IL). Data were analyzed for normal distribution using the KolmogorovSmirnov test. Values were expressed as mean $\pm \mathrm{SD}$, and the paired-t test was used to determine significant differences among group means $(\mathrm{P}<0.01)$.

\section{RESULTS}

The results of the torsion angle, neck-shaft angle, and FO, which were measured using our gauge, are listed in Table I. The torsion angles of left and right male femurs were
$7.08 \pm 9.30^{\circ}$ and $6.02 \pm 10.85^{\circ}$, respectively. We found no significant difference between the paired values $(\mathrm{P}>0.05)$. However, the data in Table I indicate that there were systematic differences between the left and right femurs for FO and neck-shaft angle $(\mathrm{P}<0.01)$. Furthermore, with regard to FO, there was a significant difference between the males and females.

On the basis of the measured data, the regression equation among $\mathrm{FO}$, torsion angle, and neck-shaft angle was obtained mathematically. The regression equation is $\mathrm{Y}=a+b x$ or $y=a+b_{1} x_{1}+b_{2} x_{2}$ ( $\mathrm{Y}=$ dependent variable, $a=$ intercept, $b=$ regression coefficient, $x\left\{\right.$ or $\left.x_{1}, x_{2}\right\}=$ dependent variable). The detailed calculation is shown in Table II.

Table I. The data of FO, neck-shaft angle and torsion angle $(n=50,-? \pm \mathrm{SD})$ The data were obtained from the gauge. And values are expressed as means \pm SD. ${ }^{\text {abcdef }}$ Groups sharing the same letter are significantly different from one another $(\mathrm{P}<0.01)$.

\begin{tabular}{|c|c|c|c|c|c|c|}
\hline \multirow{2}{*}{ Item } & \multicolumn{2}{|r|}{ Male $(n=50)$} & \multicolumn{2}{|r|}{ Female $(n=50)$} & \multirow{2}{*}{$t$} & \multirow{2}{*}{$P$} \\
\hline & Sideness & Mean \pm SD (min-max) & Sideness & Mean \pm SD (min-max) & & \\
\hline \multirow{3}{*}{$\begin{array}{l}\text { Torsion } \\
\text { angle }\left({ }^{\circ}\right)\end{array}$} & Right & $6.02 \pm 10.85(-12-28)$ & Right & $10.02 \pm 11.69(-16-35)$ & 1.77 & 0.79 \\
\hline & Left & $7.08 \pm 9.30(-7-29)$ & Left & $6.02 \pm 10.85(-8-31)$ & 1.42 & 0.16 \\
\hline & Summation & $6.55 \pm 9.56(-12-29)$ & Summation & $8.02 \pm 11.40(-16-35)$ & & \\
\hline \multirow{3}{*}{$\begin{array}{l}\text { Neck-shaft } \\
\text { angle }\left({ }^{\circ}\right)\end{array}$} & Right & $131.80 \pm 4.36^{\mathrm{a}}(120-141)$ & Right & $132.10 \pm 5.94$ ь (107-145.5) & 0.32 & 0.75 \\
\hline & Left & $134.00 \pm 4.78^{\mathrm{a}}(121-144)$ & Left & $132.80 \pm 4.93^{\mathrm{b}}(122-150)$ & 1.22 & 0.23 \\
\hline & Summation & $132.90 \pm 4.11(120-144)$ & Summation & $132.40 \pm 4.80(107-150)$ & & \\
\hline \multirow{3}{*}{$\begin{array}{l}\text { Femoral } \\
\text { offset (mm) }\end{array}$} & Right & $44.40 \pm 4.56^{\text {c e }(33-54)}$ & Right & $39.90 \pm 6.00^{\mathrm{de}}(24-51)$ & 4.27 & 0.01 \\
\hline & Left & $42.70 \pm 4.95^{\mathrm{c} \mathrm{f}}(23-56)$ & Left & $38.90 \pm 6.18 \mathrm{~d}^{\mathrm{f}}(21-50)$ & 3.41 & 0.01 \\
\hline & Summation & $43.60 \pm 4.47(23-56)$ & Summation & $39.40 \pm 5.85(21-51)$ & & \\
\hline
\end{tabular}

Table II. The regression equation among femoral offset, neck-shaft angle and torsion angle (femoral offset=FO, neck-shaft angle=NSA, torsion angle=TA, Lengh: mm, Angle: ${ }^{\circ}$ )

\begin{tabular}{lc}
$\mathrm{y}=\mathrm{a}+\mathrm{bX}$ or $\mathrm{y}=\mathrm{a}+\mathrm{b}_{1} \mathrm{X}_{1}+\mathrm{b}_{2} \mathrm{X}_{2}$ & $F$ \\
\hline $\mathrm{FO}=118.18-0.564$ NSA-0.227 TA & 40.549 \\
FO (right) $=108.18-0.489$ NSA (right)_0.185TA (right) & 34.686 \\
FO (left) $=117.87-0.524$ NSA (left)-0.256 TA (left) & 35.275 \\
FO $=132.00-0.682$ NSA & 41.109 \\
FO(right) $=121.77-0.603$ NSA (right) & 40.735 \\
FO(left) $=117.93-0.579$ NSA (left) & 29.007 \\
FO =43.82-0.284 TA & 35.171 \\
FO (right) $=44.15-0.248$ TA (right) & 30.803 \\
FO (left) $=43.17-0.281$ TA (left) & 30.179 \\
NSA $=152.01-0.03$ TA_0.461 FO & 20.676 \\
NSA (right) $=152.03-0.478$ FO (right) +0.009 TA (right) & 20.190 \\
NSA (left) $=152.93-0.463$ FO (left)-0.082 TA (left) & 16.281 \\
TA $=70.98 \_0.161$ NSA-0.999 FO & 17.723 \\
TA (right) $=41.47+0.048$ NSA (right)_0.943 FO (right) & 15.272 \\
TA (left) $=95.30+0.352$ NSA (left)_0.976 FO (left) & 16.816 \\
\hline
\end{tabular}

\section{DISCUSSION}

Total hip arthroplasty, as a therapeutic intervention for hip disease, has been performed for many years. The desired goals of THA are symptom relief and restoration of hip biomechanics. To optimize function, hip anatomy should be restored to as near normal as possible. One of the main challenges of modern THA is to restore leg length and provide optimal FO. Even with the new techniques and technology available, this still proves to be technically challenging (Herman $e t$ al., 2011). Some previous studies indicate that FO was correlated with hip stability, joint reaction forces, $\mathrm{PE}$ wear, postoperative pain and ROM (Bourne \& Rorabeck, 2002; Matsushita et al., 2009; Little et al.; Cassidy et al., 2012). Consequently, restoring native FO is an important determinant of the success of THA.

With regard to measuring $\mathrm{FO}$, some methods have been described in previous publications, but little is known about the most accurate method. Radiological methods of measuring FO usually were used in clinical studies. Based on measurements in 200 anteroposterior pelvic radiographs, Massin et al. 
(2000) found that the value of FO was $41.0 \pm 6.2 \mathrm{~mm}$. Sariali et al. (2009) analyzed 223 patients with osteoarthritic hips using 3-dimensional CT-scan and found that the mean FO was $42.2 \pm 5.1 \mathrm{~mm}$. Moreover, they found that the X-ray technique generally underestimated the FO, with an error of $3.5 \pm 2.5 \mathrm{~mm}$. Other studies also demonstrated that plain radiography underestimates the FO measurement and that when comparing FO measured by conventional X-ray and CT-scan, the CT-scan was more accurate (Bourne \& Rorabeck; Lecerf et al. 2009). Merle et al. (2012) suggested that FO was significantly underestimated on AP radiographs of the pelvis but could be accurately assessed on AP radiographs of the hip. However, the same researchers also considered that FO could be reliably predicted from AP pelvis radiograph (Merle et al., 2013). In addition, QCT (Ramamurthi et al.), imageless navigation system (Renkawitz et al.) and dual-energy x-ray absorptiometry (DXA) (LaCroix et al., 2010), as the measurement methods of FO had been mentioned in some studies.

However, there is no method of measurement that has been performed on femur specimen, and the internal relationship between FO, neck-shaft angle and torsion angle has not been mentioned. Therefore, we designed the study, and obtained satisfactory results through measurement and analysis. In our study, the mean FO was found to be $42.70 \pm 4.95 \mathrm{~mm}$ (left) and $44.40 \pm 4.56 \mathrm{~mm}$ (right) in male femur specimen, and $38.90 \pm 6.18 \mathrm{~mm}$ (left) and $39.90 \pm 6.00$ $\mathrm{mm}$ (right) in female femur specimen. The results indicated that there were significant differences for FO not only between the male and female but also between the right and left, and this should be considered when planning THA.

Prasad et al. (1996) measured the femoral torsion angle in unpaired femurs $(\mathrm{n}=171)$, and found that the angle ranged from -9 to $+35^{\circ}$ with a mean of $+12.3^{\circ}$, and was not correlated with the linea aspera, neck-shaft angle, or femoral length. Computed tomography was considered the method of choice for detecting the femoral torsion angle. However, another study indicated that $\mathrm{CT}$ measurements of the femoral torsion angle were not accurate, due principally to the difficulty in defining a line through the axis of the femoral neck (Jaarsma et al., 2004). Other investigators think that use of the trochanteric prominence angle test to measure the femoral torsion angle is as accurate as the limited three-dimensional volumetric tomography technique (Delialioglu et al., 2006). In our study, the femoral torsion angle was obtained in the gauge through measuring 100 pairs of intact femur specimens. The mean torsion angle was $7.08 \pm 9.30^{\circ}$ (left) and $6.02 \pm 10.85^{\circ}$ (right) in male femur specimens, and $6.02 \pm 10.85^{\circ}$ (left) and $10.02 \pm 11.69^{\circ}$ (right) in female femur specimens. Ollivier $e t$ al. (2013) had used standing antero-posterior long-leg radiographs to determine femoral offset, neck-shaft angle, and not analyzed the correlation of FO and NSA. In our study, we not only obtained the data of neck-shaft angle, but also the regression equation among them.

In previous literature, FO, torsion angle, and neckshaft angle were measured and analyzed using various methods. However, there was no study on the relationship among FO, torsion angle, and neck-shaft angle. In this study, on the basis of the measured data, the regression equation among FO, torsion angle, and neck-shaft angle was $\mathrm{Y}=a+b x$ or $y=a+b_{I} x_{1}+b_{2} x_{2}$. Moreover, according to the results of our statistical analysis, FO could be obtained using the regression equation when torsion angle, and/or neck-shaft angle was measured. Thus, our study not only first measured FO, torsion angle and neck-shaft angle, but also obtained the regression equation among them. The results might provide a new method to obtain FO without the need for measurement every data. However, the data from regression equation should be contrasted with the data from AP pelvis radiographs or CT-scan in patients to validate the accuracy of the regression equation. In this way, our method and finding would be applied to guide the clinical work.

HAN, M.; ZHANG, Y. \& SHAN, T. Desplazamiento femoral y su relación con el ángulo cuello-diáfisis femoral y el ángulo de torsión. Int. J. Morphol., 32(4):1194-1198, 2014.

RESUMEN: El objetivo fue estudiar el desplazamiento femoral y su relación con el ángulo cuello-diáfisis femoral y el ángulo de torsión. Se utilizaron 100 pares de fémures (50 hombres y 50 mujeres) y se tomaron las medidas del desplazamiento femoral, ángulo cuello-diáfisis femoral y ángulo de torsión. Los datos fueron analizados con el software SPSS. El desplazamiento femoral en los hombres fue 44,40 $\pm 4,56 \mathrm{~mm}$ en el lado derecho y $42,70 \pm 4,95$

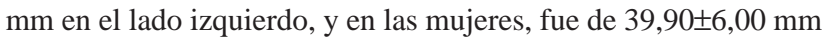
y $38,90 \pm 6,18 \mathrm{~mm}$ para el lado derecho e izquierdo, respectivamente. El ángulo de torsión femoral del lado derecho en los hombres fue $6,02 \pm 10,85^{\circ}$ y $7,08 \pm 9,30^{\circ}$ del izquierdo; mientras que en las mujeres, fue de $10,02 \pm 11,69^{\circ}$ y $6,02 \pm 10,85^{\circ}$ para el lado derecho e izquierdo, respectivamente. Los ángulos cuello-diáfisis fueron $131,80 \pm 4,36^{\circ}$ en el lado derecho, y $134,00 \pm 4,78^{\circ}$ en el izquierdo, para los hombres, mientras que en las mujeres fueron de $132,10 \pm 5,94^{\circ}$ en el lado derecho y $132,80 \pm 4,93^{\circ}$ en el izquierdo. No hubo diferencias según sexo en los dos ángulos femorales $(\mathrm{P}>0,05)$, mientras que si hubo una diferencia significativa en el desplazamiento femoral $(\mathrm{P}<0,01)$. Las diferencias entre el desplazamiento femoral izquierdo y derecho, y el ángulo cuello-diáfisis fueron significativas $(\mathrm{P}<0,01)$. Clínicamente, nuestros resultados indican que el desplazamiento femoral podría obtenerse utilizando la ecuación de regresión cuando se mide el ángulo de torsión o el ángulo cuello-diáfisis.

PALABRAS CLAVE: Desplazamiento femoral; Ángulo de cuello femoral; Ángulo de torsion femoral; Diseño de prótesis. 


\section{REFERENCES}

Barrack, R. L. Factors influencing polyethylene wear in total joint arthroplasty. Orthopedics, 21(9):937-40, 1998.

Bourne, R. B. \& Rorabeck, C. H. Soft tissue balancing: the hip. $J$. Arthroplasty, 17(4 Suppl. 1):17-22, 2002.

Cassidy, K. A.; Noticewala, M. S.; Macaulay, W.; Lee, J. H. \& Geller, J. A. Effect of femoral offset on pain and function after total hip arthroplasty. J. Arthroplasty, 27(10):1863-9, 2012.

Dastane, M.; Dorr, L. D.; Tarwala, R. \& Wan, Z. Hip offset in total hip arthroplasty: quantitative measurement with navigation. Clin. Orthop. Relat. Res., 469(2):429-36, 2011.

Delialioglu, M. O.; Tasbas, B. A.; Bayrakci, K.; Daglar, B.; Kurt, M.; Agar, M. \& Gunel, U. Alternative reliable techniques in femoral torsion measurement. J. Pediatr. Orthop. B., 15(1):28-33, 2006.

Devane, P. A. \& Horne, J. G. Assessment of polyethylene wear in total hip replacement. Clin. Orthop. Relat. Res., (369):59-72, 1999.

Herman, K. A.; Highcock, A. J.; Moorehead, J. D. \& Scott, S. J. A comparison of leg length and femoral offset discrepancies in hip resurfacing, large head metal-on- metal and conventional total hip replacement: a case series. J. Orthop. Surg. Res., 6:65, 2011.

Jaarsma, R. L.; Bruggeman, A. W.; Pakvis, D. F.; Verdonschot, N.; Lemmens, J. A. \& van Kampen, A. Computed tomography determined femoral torsion is not accurate. Arch. Orthop. Trauma Surg., 124(8):552-4, 2004.

LaCroix, A. Z.; Beck, T. J.; Cauley, J. A.; Lewis, C. E.; Bassford, T.; Jackson, R.; Wu, G. \& Chen, Z. Hip structural geometry and incidence of hip fracture in postmenopausal women: what does it add to conventional bone mineral density? Osteoporos. Int. 21(6):919-29, 2010.

Lecerf, G.; Fessy, M. H.; Philippot, R.; Massin, P.; Giraud, F.; Flecher, X.; Girard, J.; Mertl, P.; Marchetti, E. \& Stindel, E. Femoral offset: anatomical concept, definition, assessment, implications for preoperative templating and hip arthroplasty. Orthop. Traumatol. Surg. Res., 95(3):210-9, 2009.

Little, N. J.; Busch, C. A.; Gallagher, J. A.; Rorabeck, C. H. \& Bourne, R. B. Acetabular polyethylene wear and acetabular inclination and femoral offset. Clin. Orthop. Relat. Res., 467(11):2895-900, 2009.

Massin, P.; Geais, L.; Astoin, E.; Simondi, M. \& Lavaste, F. The anatomic basis for the concept of lateralized femoral stems: a frontal plane radiographic study of the proximal femur. J. Arthroplasty, 15(1):93-101, 2000.

Matsushita, A.; Nakashima, Y.; Jingushi, S.; Yamamoto, T.; Kuraoka, A. \& Iwamoto, Y. Effects of the femoral offset and the head size on the safe range of motion in total hip arthroplasty. J. Arthroplasty, 24(4):646-51, 2009.

McGrory, B. J.; Morrey, B. F.; Cahalan, T. D.; An, K. N. \& Cabanela,
M. E. Effect of femoral offset on range of motion and abductor muscle strength after total hip arthroplasty. J. Bone Joint Surg. Br., 77(6):865-9, 1995.

Merle, C.; Waldstein, W.; Pegg, E. C.; Streit, M. R.; Gotterbarm, T.; Aldinger, P. R.; Murray, D. W. \& Gill, H. S. Prediction of threedimensional femoral offset from AP pelvis radiographs in primary hip osteoarthritis. Eur. J. Radiol., 82(8):1278-85, 2013.

Merle, C.; Waldstein, W.; Pegg, E.; Streit, M. R.; Gotterbarm, T.; Aldinger, P. R.; Murray, D. W. \& Gill, H. S. Femoral offset is underestimated on anteroposterior radiographs of the pelvis but accurately assessed on anteroposterior radiographs of the hip. $J$. Bone Joint Surg. Br., 94(4):477-82, 2012.

Ollivier, M.; Parratte, S.; Lecoz, L.; Flecher, X. \& Argenson, J. N. Relation between lower extremity alignment and proximal femur anatomy. Parameters during total hip arthroplasty. Orthop. Traumatol. Surg. Res., 99(5):493-500, 2013.

Pasquier, G.; Ducharne, G.; Ali, E. S.; Giraud, F.; Mouttet, A. \& Durante E. Total hip arthroplasty offset measurement: is C T scan the most accurate option? Orthop. Traumatol. Surg. Res., 96(4):367$75,2010$.

Prasad, R.; Vettivel, S.; Isaac, B.; Jeyaseelan, L. \& Chandi, G. Angle of torsion of the femur and its correlates. Clin. Anat., 9(2):109-17, 1996.

Ramamurthi, K.; Ahmad, O.; Engelke, K.; Taylor, R. H.; Zhu, K.; Gustafsson, S.; Prince, R. L. \& Wilson, K. E. An in vivo comparison of hip structure analysis (HSA) with measurements obtained by QCT. Osteoporos. Int., 23(2):543-51, 2012.

Renkawitz, T.; Schuster, T.; Herold, T.; Goessmann, H.; Sendtner, E.; Grifka, J. \& Kalteis, T. Measuring leg length and offset with an imageless navigation system during total hip arthroplasty: is it really accurate? Int. J. Med. Robot., 5(2):192-7, 2009.

Sariali, E.; Mouttet, A.; Pasquier, G. \& Durante, E. Three-dimensional hip anatomy in osteoarthritis. Analysis of the femoral offset. $J$. Arthroplasty, 24(6):990-7, 2009.

\section{Correspondence to: \\ Ming Han}

Department of Orthopedics

Affiliated Hospital of Shandong University of Traditional

Chinese Medicine

Jinan 250011

Shandong Province

CHINA

Email: minghancn@163.com

Received: 16-04-2014

Accepted: 31-07-2014 